\title{
Bioequivalence of Two Oral Extended Release Formulations of Ciprofloxacin Tablets in HealthyMale Volunteers under Fed and Fasting Conditions
}

\author{
Derar M. Omari*, Dalia Johary, Isam I. Salem, Naji Najib and Assayed A.Sallam
}

Faculty of Pharmacy, Alzaytoonah Private University of Jordan, Amman, Jorda

\begin{abstract}
The bioavailability of a single dose of ciprofloxacin $1000 \mathrm{mg}$ Extended release $(\mathrm{XR})$ tablets manufactured by a Jordanian manufacturer (Hikma PLC), was compared with a reference ciprofloxacin $1000 \mathrm{mg}$ XR tablets (Cipro® XR, Bayer-health care, Germany) in two different studies (under fasting and fed conditions). In each study, 28 healthy, male, Jordanian volunteers were enrolled. However, only 25 subjects in fasting study and 23 subjects in fed study completed the crossover. Each study was designed as single-center, open-label, randomized, singledose, two-way crossover study. Nineteen blood samples were taken during $24 \mathrm{hrs}$. Samples were frozen and kept until time of analysis. Ciprofloxacin concentrations in subjects' plasma were determined by using a validated HPLC fluorescence technique. Confidence intervals $(90 \%)$ for the peak plasma concentration $\left(C_{\text {max }}\right)$ and area under the concentration-time curve (AUCO-t) were determined by calculating log-transformed Test/Reference ratio using standard non-compartmental method and ANOVA statistics. The $90 \% \mathrm{Cl}$ result in fasting study for $\mathrm{C}_{\text {max }}$ was 88.87 (82.17 - 96.10)\% and for AUC0-t was $87.60(80.38-95.46) \%$. In fed study the results were $102.09(92.77-112.34) \%$ and 104.06 (100.01-108.27)\% for ${ }_{C \max }$ and AUC0-t, respectively. In conclusion, it is evident that the $90 \% \mathrm{Cl}$ for the primary pharmacokinetics parameters was within the bioequivalence acceptable boundaries of $80-125 \%$, while for AUC0-t, and $75 .-133 \%$ for $C_{\max }$. Therefore, it was concluded that both products were bioequivalent.
\end{abstract}

Keywords: Ciprofloxacin; Extended Release; Pharmacokinetics; Bioavailability; Bioequivalence

\section{Introduction}

Ciprofloxacin is a quinoline carboxylic acid derivative with broad antibacterial activity against both gram-positive and gram-negative bacteria. Chemically it is 1-cyclopropyl-6-fluoro-1,4-dihydro-4-oxo-7(1-piperazinyl)-3-quinolinecarboxylic acid] [3, 5,11]. It was found to be more active against enterobacteriaceae than the older drugs of this class, such as nalidixic acid, with minimum inhibitory concentrations ranging from 0.008 to $2.0 \mathrm{mg} / \mathrm{l}[3,4]$. The adverse effects are also less likely [7]. Ciprofloxacin extended release is indicated only for the treatment of urinary tract infections, including acute uncomplicated pyelonephritis, caused by susceptible strains. Ciprofloxacin XR and ciprofloxacin immediate-release tablets are not interchangeable [6].

Once-daily ciprofloxacin XR was safe, effective, and noninferior to twice-daily ciprofloxacin immediate-release (IR) in the treatment of acute UTI. Additionally, ciprofloxacin XR was associated with significantly reduced frequencies of nausea and diarrhea. $[8,12,15,19,14]$. [18] showed that ciprofloxacin XR possessed larger AUCs than levofloxacin. Patients' compliance improvement using ciprofloxacin XR and thus decrease the risk of treatment failure and the spread of antibiotic resistance are also reported [17]. Furthermore, since economic considerations are increasingly important and using $\mathrm{XR}$ treatments prove convenient and effective in this regards [12]. Maximum plasma ciprofloxacin concentrations are attained between 1 and 4 hours after dosing with Ciprofloxacin XR. In comparison to the $250 \mathrm{mg}$ and $500 \mathrm{mg}$ ciprofloxacin IR BID treatment, the $\mathrm{C}_{\max }$ of Ciprofloxacin XR $500 \mathrm{mg}$ and $1000 \mathrm{mg}$ once daily are higher than the corresponding BID doses, while the AUCs over 24 hours are equivalent. The IT decreases the rate, but not the extent, of drug absorption. Antacids containing magn-esium, aluminum and/or calcium decrease the bioavailability of ciprofloxacin. The plasma half-life is about 3.5-4.5 hours and there is an evidence of modest accumulation [6].
Studies to establish bioequivalence (BE) between two products are important for certain changes before approval regulatory submissions. In BE studies, an applicant compares the systemic exposure profile of a test drug product to that of a reference drug product. For two orally administered drug products to be bioequivalent, the active drug ingredient or active moiety in the test product must exhibit equivalent rate and extent of absorption to that of the reference drug product. Product quality BE frequently relay on pharmacokinetics measures such as AUC and $C_{\max }$ that are reflective of systemic exposure [9]. For modified-release products, the following studies are recommended: (1) a single-dose, nonreplicate, fasting study comparing the highest strength of the test and reference listed drug product and (2) a foodeffect, nonreplicate study comparing the highest strength of the test and reference product. For immediate release products, a single-dose, fasting study is recommended. In addition, in vivo BE studies are to be accompanied by in vitro dissolution profiles on all strengths of each product.

Literature showed many bioequivalence studies for ciprofloxacin immediate release tablets $[2,1]$, while no bioequivalence studies were published on the $1000 \mathrm{mg}$ XR formulation. The aim of this study was to determine bioequivalence of two XR tablet formulations: Ciprofloxacin

*Corresponding author: Dr. Derar M Omari, Pofessor, Faculty of Pharmacy Alzaytoonah Private University of Jordan, Amman, Jorda, Tel: 00962795013327 Fax: 0096265536015; E-mail: d_omari@hotmail.com

Received February 02, 2011; Accepted March 28, 2011; Published March 30 2011

Citation: Omari DM, Johary D, Salem II, Najib N, Sallam AA (2011) Bioequivalence of Two Oral Extended Release Formulations of Ciprofloxacin Tablets in HealthyMale Volunteers under Fed and Fasting Conditions. J Bioequiv Availab 3: 038-042. doi:10.4172/jbb.1000055

Copyright: (c) 2011 Omari DM, et al. This is an open-access article distributed under the terms of the Creative Commons Attribution License, which permits unrestricted use, distribution, and reproduction in any medium, provided the original author and source are credited. 
XR 1000mg tablet (Hikma pharmaceutical-PLC) relative to [6] tablets (Bayer Health care-Germany) after oral administration to healthy volunteers under both fed and fasting conditions.

\section{Subjects and Methods}

\section{Subjects}

Table 1 shows number and demographic data for subjects enrolled in the two studies, fast and fed. In either study, 28 subjects were enrolled, however, 3 in fasting and 5 in fed withdrew due to personal reasons or medical conditions before study drug administration. Consequently, a total of 25 and 23 subjects completed the crossover in fast and fed, respectively. All subjects were healthy, adults, male Jordanian volunteers. Clinical results of the screened laboratory examinations (biochemistry, serology, hematology and urine analysis) were within normal ranges. All subjects were informed with the objectives, drugs, potential risks, dates and activities during the clinical part of the study. A written consent form was signed by each subject. Any subject having drug allergy, alcohol abuse, GIT conditions that may have significantly affected drug absorption, etc., was excluded. The use of either prescription or OTC drugs was abstained 2 weeks before study time.

Both Fasting and fed studies were approved by The Institutional Review Board (IRB) of IPRC, Amman, Jordan, which operates in accordance with the principles and requirements described in Guidelines on Research Involving Human Subjects. The study protocols were reviewed by IRB of IPRC, approved and given the code Nos.CIP-T015 and CIP-T016 for fasting and fed studies respectively.

\section{Study drugs}

Two products of Ciprofloxacin 1000mg XR tablets were studied. The test product was Ciprofloxacin 1000mg XR tablets (HikmaPharma, Jordan, B\# JE5-P9, Exp date: 04/10). The reference was [6] $1000 \mathrm{mg}$ (Bayer-Health care, Germany, B\# BXBX721, Exp. Date: 01/09). The same batches were used for fasting and fed studies.

\section{Methods}

The method was designed as single dose, two-treatment, twoperiod, two-sequence crossover with a 7-days washout period for

\begin{tabular}{|l|l|l|}
\hline Characteristic & Fasting study & Fed study \\
\hline No. enrolled & 28 & 28 \\
\hline No. completed study & 25 & 23 \\
\hline Mean age $(\mathrm{yr}) \pm S D$ & $29 \pm 7.66$ range18-43yr & $25 \pm 5.92$ range $19-43 \mathrm{yr}$ \\
\hline Mean body wt $(\mathrm{Kg}) \pm S D$ & $70 \pm 7.44$ range54-85kg & $75 \pm 11.59$ range60-100kg \\
\hline Mean height $(\mathrm{cm}) \pm S D$ & $171 \pm 5.69$ range $163-186 \mathrm{~cm}$ & $175 \pm 6.48$ range $163-190 \mathrm{~cm}$ \\
\hline
\end{tabular}

Table 1: number of subjects enrolled in the study and their demographic characteristics.

\begin{tabular}{|l|l|l|l|}
\hline day & Meal & Fasting study & Fed study \\
\hline-1 & Dinner & $\begin{array}{l}\text { Finished at least 10 } \\
\text { hours before time of drug } \\
\text { administration in day 1 }\end{array}$ & $\begin{array}{l}\text { Finished at least 10 hours before } \\
\text { time of drug administration in } \\
\text { day 1 }\end{array}$ \\
\hline 1 & Breakfast & None & $\begin{array}{l}\text { 0.5hours before drug } \\
\text { administration }\end{array}$ \\
\hline 1 & Lunch & $\begin{array}{l}4 \text { hours after drug } \\
\text { administration }\end{array}$ & 5 hours after drug administration \\
\hline 1 & Snack & $\begin{array}{l}\text { 8 hours after drug } \\
\text { administration }\end{array}$ & 9 hours after drug administration \\
\hline 1 & dinner & $\begin{array}{l}12 \text { hours after drug } \\
\text { administration }\end{array}$ & $\begin{array}{l}13 \text { hours after drug } \\
\text { administration }\end{array}$ \\
\hline
\end{tabular}

Table 2: Food times before and after drug administration. each study. Subjects were admitted the night before the study drug administration, supervised for at least 10 hours overnight fasting, and confined until collecting the 24 hour sample. On day 1 of each study period, each subject was given either one tablet of Ciprofloxacin 100mg XR tablet (test product) or Cipro XR 1000mg (Reference product) according to a randomization plan, along with $240 \mathrm{ml}$ of water. Diet consumption before and after drug administration are shown in Table 2.

The consumption of alcohols, methylxanthin-containing beverages (coffee, etc.) or grapefruits were prohibited enough time prior to drug administration. Physical activities were controlled throughout the study period. For blood samples collection, a cannula was inserted to each subject's forearm vein and remain there until the 24-hour sample. Eight milliliters blood was collected each sample as follows: immediately before at 0.00 (predose) and at $0.50,1.00,1.50,2.00$, $2.50,3.00,3.50,4.00,4.50,5.00,6.00,8.00,10.00,12.00,16.00,20.00$ and 24.00 hours. Blood samples were collected into tubes containing heparin as an anticoagulant (Dispo ${ }^{\mathrm{TM}}$, AFMA, Jordan), slightly shaken and centrifuged (at approximately $3500 \mathrm{rpm}$ ) for 10 minutes, transferred immediately to plastic tube (Dispo ${ }^{\mathrm{TM}}$, AFMA, Jordan) and stored at $-20^{\circ} \mathrm{C}$. The total amount of blood loss during the whole study did not exceed $317.5 \mathrm{ml}$.

Ciprofloxacin concentrations in human plasma were determined by a specific high performance liquid chromatography (HPLC) with fluorescence detection method. The technique was developed at IPRC laboratories. After spiking $200 \mu \mathrm{l}$ of plasma samples with levofloxacin as internal standard, a protein precipitation technique using $1 \mathrm{ml}$ methanol was employed to extract both analytes. Supernatants then were centrifuged, evaporated to dryness under nitrogen gentle stream and reconstituted with $800 \mu \mathrm{l}$ mobile phase. Only $20 \mu \mathrm{l}$ were injected into a prepacked C18, $5 \mu \mathrm{m}(3.9 \times 150 \mathrm{~mm})$ reversed phase analytical column. Mobile phase was composed of $7 \%$ glacial acetic acid, 5\% acetonitrile and $88 \%$ ( $0.025 \mathrm{M}$ sodium acetate trihydrate), with flow rate at $1.50 \mathrm{ml} / \mathrm{min}$. Separations were monitored at 280 and $440 \mathrm{~nm}$ as excitation and emission wavelengths, respectively. Analysis was accomplished at column oven temperature $25^{\circ} \mathrm{C}$. Chromatography separation and drug determination was accomplished by using Shimadzu (Japan) HPLC composed of LC-10AD vp pump, RF- 10A $\mathrm{XL}$ fluorescence detector and SCL-10A vp system controller.

The method was validated according to the FDA current bioanalytical guidance. Accordingly the method validation was evaluated in terms of specificity, selectivity, linearity, sensitivity, inter and intraday accuracy and precision, recovery and stability under different conditions. Samples from 25 subjects in fasting study and 23 subjects in fed study were analyzed.

\section{Pharmacokinetic calculations}

Pharmacokinetic parameters of ciprofloxacin were estimated using standard non-compartmental methods. The maximal plasma concentration $\left(\mathrm{C}_{\max }\right)$ and the time to the peak plasma concentration $\left(\mathrm{t}_{\max }\right)$ of ciprofloxacin were taken directly from the measured data. The area under the plasma concentration-time curve $\left(\mathrm{AUC}_{0-\mathrm{t}}\right)$ was calculated from measured data points from time of administration to time of last quantifiable concentration $\left(\mathrm{C}_{\text {last }}\right)$ by the linear trapezoidal rule. The area under the plasma concentration-time curve extrapolated to infinity $\left(\mathrm{AUC}_{0-\infty}\right)$ was calculated according to the following formula: $\mathrm{AUC}_{0-\infty}=\mathrm{AUC}_{0-\mathrm{t}}+\mathrm{C}_{\text {last }} /\left[\ln 2 / \mathrm{t}_{1 / 2 \mathrm{e}}\right]$ where $\mathrm{C}_{\text {last }}$ is the last quantifiable concentration. The ratio $\mathrm{AUC}_{0-\mathrm{t}} / \mathrm{AUC}_{0-\infty}$ as a percent was determined as an indicator for the adequacy of sampling time. The elimination 
half-life $\left(\mathrm{t}_{1 / 2 \mathrm{e}}\right)$ was calculated as: $\mathrm{t}_{1 / 2 \mathrm{e}}=\operatorname{Ln}(2) /(-\mathrm{b})$, where b was obtained as the slope of the linear regression of the Ln-transformed plasma concentrations versus time in the terminal period of the plasma curve. The pharmacokinetic calculations were performed on a Pentium MMX $\mathrm{MHz}$ Computer using the computer program Kinetica ${ }^{\mathrm{TM}} 2000$.

\section{Statistical analysis}

Statistical analysis was performed by using the Kinetica ${ }^{\text {TM }} 2000$ program, with the aid of Microsoft ${ }^{\circledR}$ Excel (2002).The extent of absorption is determined by $\mathrm{AUC}_{0-\mathrm{t}}$ and $\mathrm{AUC}_{0-\infty}$. The rate of absorption is determined by $\mathrm{C}_{\max }$. For the parametric analysis of bioequivalence for Ln-transformed data, the acceptance boundaries were set at $80.00-125.00 \%$ for both $\mathrm{AUC}_{0-\mathrm{t}}$, and $\mathrm{C}_{\text {max. }}$ A multiplicative model with respect to the untransformed bioequivalence parameters was selected. A logarithmic transformation of the original data was used. Under the assumption of a logarithmic normal distribution, a parametric approach recommended by [16] based on the inclusion of the shortest $90 \%$ confidence interval in the bioequivalence range was adopted. An analysis of variance (ANOVA) tested for sequence, period, subject (sequence) and treatment effects was used. ANOVA was performed on $\mathrm{AUC}_{0-\mathrm{t}}, \mathrm{AUC}_{0-\infty}, \mathrm{C}_{\max }, \mathrm{t}_{\max }, \mathrm{t}_{1 / 2 \mathrm{e}}, \mathrm{K}_{\mathrm{e}}, \mathrm{Ln}_{\mathrm{AUC}}, \mathrm{Ln} \mathrm{AUC}_{0-\infty}$ and $\mathrm{Ln} \mathrm{C}_{\text {max }}$.

A multiplicative linear model was used for the two-way crossover design:Yijk $=\log ($ Xijk $)=\mu+$ Gk Sik + Pj $+F(j, k)+$ eijk, Where, Yijk $=$ is a pharmacokinetic parameter of the ith subject $\left(i=1,2, \ldots n_{k}\right)$ in the sequence $(k=1,2, \ldots k)$ for the jth period $(j=1,2, \ldots p) ; \mu$ : is the overall mean; Gk: is the fixed effect of the kth sequence; Sik: is the random effect of the ith subject in the kth sequence; $\mathrm{Pj}$ : is the fixed effect of the jth period; $F(j, k)$ : is the fixed effect of the formulation in the kth sequence, which is administered at the jth period; and, eijk: is the ( within subject ) random error in observing Yijk.It was assumed that $\{\mathrm{Sik}\}$ and $\{$ eijk $\}$ are mutually independent and normally distributed with mean zero and variances $\sigma s^{2}$ and $\sigma e^{2}$.

\section{Results}

The described analytical method was proved selective and specific. Retention times were 7.4 and $8.8 \mathrm{~min}$ for the internal standard and drug, respectively. No interferences were observed. Concomitant drugs do not interfere with ciprofloxacin or internal standard analysis. The method was proved sensitive and accurate for the determination of ciprofloxacin in human plasma. Under the described conditions, the limit of quantitation for ciprofloxacin was $50 \mathrm{ng} / \mathrm{ml}$ with $99.60 \%$ accuracy and $15.06 \% \mathrm{CV}$. The method was found linear within the range $50-5000 \mathrm{ng} / \mathrm{ml}$, with accuracy ranging $99.15-100.70 \%$ and precision $0.98-15.06 \%$. Correlations coefficients were 0.99 . Intraday accuracy of ciprofloxacin method ranged from 94.93 to $97.80 \%$, while precision

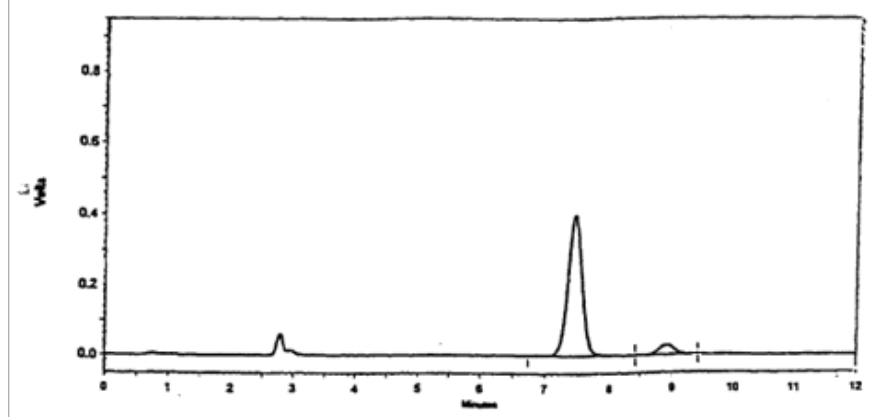

Figure 1: HPLC chromatogram showing human plasma containing $150 \mathrm{ng} / \mathrm{ml}$ ciprofloxacin at retention time $9 \mathrm{~min}$ and internal standard levofloxacin peak at $7 \mathrm{~min}$.
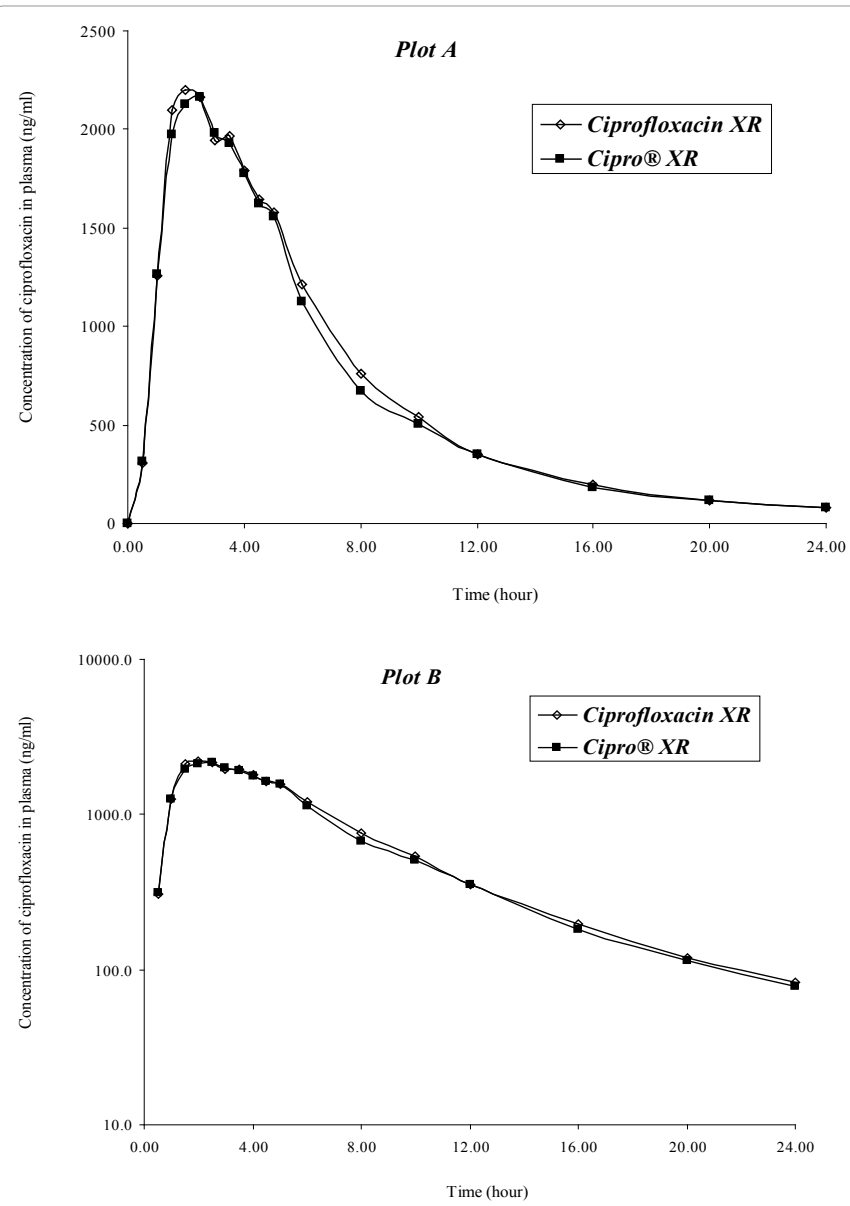

Figure 2: Ciprofloxacin mean plasma concentration after an oral dose administration of $1000 \mathrm{mg}$ Ciprofloxacin from Ciprofloxacin XR, $1000 \mathrm{mg}$ Ciprofloxacin per extended release tablet (Test Product) and Cipro ${ }^{\circledR}$ XR,1000 $\mathrm{mg}$ Ciprofloxacin per Tablet (Reference Product) to 25 healthy subjects under fed conditions (Plot A: plasma conc. vs time, Plot B: log transformed plasma conc vs time).

ranged from 1.24 to $5.73 \%$. Interday accuracy ranged from 95.00 to $99.31 \%$, while the interday precision ranged from 4.07 to $7.58 \%$. Mean recovery was proved $86.57 \%$ with $7.74 \% \mathrm{CV}$. Ciprofloxacin long-term stability was tested and was found stable for 90 days at $-20^{\circ} \mathrm{C}(99.59 \%$ with $1.09 \% \mathrm{CV}$ ).

Drug plasma levels were designated as surrogate parameters to indicate clinical activity. Primary pharmacokinetic parameters were set to be $\mathrm{C}_{\max }$ and $\mathrm{AUC}_{0-\mathrm{t}}$ were also considered to be the bioequivalence determinants. Finally, $\mathrm{K}_{\mathrm{e}}, \mathrm{AUC}_{0-\infty}, \mathrm{t}_{\max }, \mathrm{AUC}_{0-\mathrm{t}} / \mathrm{AUC}_{0-\infty}$ and $\mathrm{t}_{1 / 2 \mathrm{e}}$ were set as the secondary pharmacokinetic parameters. The detailed results for fasting and fed studies are shown in Tables 3-6, respectively. Bioequivalence could be demonstrated for Ciprofloxacin within the prescribed $90 \%$ confidence interval of $80.00-125.00 \%$ for $\mathrm{AUC}_{0-\mathrm{t}}$ and $\mathrm{C}_{\max }$ with respect to the parametric method on log-transformed data. The results are shown in Figure 2 and 3 for fed and fasting studies, respectively.

\section{Discussion}

Assessment of bioequivalence of generic product to reference product is required to exclude any clinically important differences in the rate or extent at which the active entity of the drugs becomes available at the site of action. Two drug products are considered to 
Citation: Omari DM, Johary D, Salem II, Najib N, Sallam AA (2011) Bioequivalence of Two Oral Extended Release Formulations of Ciprofloxacin Tablets in HealthyMale Volunteers under Fed and Fasting Conditions. J Bioequiv Availab 3: 038-042. doi:10.4172/jbb.1000055

be bioequivalent if they are pharmaceutically equivalent and their bioavailability is so similar that they are unlikely to produce clinically relevant differences in regard to safety and efficacy [9].Food has been shown to alter the bioavailability of some drugs which can have negative impact on the interpretation of bioequivalence results between test and reference products [13]. Food can alter BA by various means, including delay gastric emptying, stimulate bile flow, change gastrointestinal (GI) $\mathrm{pH}$, increase splanchnic blood flow, change luminal metabolism of a drug substance and physically or chemically interact with a dosage form or a drug substance [9]. This effect is more pronounced in case of modified release dosage forms due to their longer stay in GIT. FDA recommends that BE study under fed conditions should be conducted for all orally administered modified-release drug product [9].

In this study, the effect of food on the bioavailability of ciprofloxacin is somewhat more noticeable for reference product (Cipro ${ }^{\circledR} \mathrm{XR}$ ) than test product. This might be due to the difference in the formulation composition. That is, the test product formula contains Ciprofloxacin $\mathrm{HCl}$ only, while that of the reference product contains a combination of ciprofloxacin base and $\mathrm{HCl}$. Thus test product will be less affected by change effect due to food. The AUC values in Table 3 and 4 shown to be higher under fasting than those under fed conditions. This effect can also be noticed if Figures 1 and 2 are compared. Furthermore, the values of $\mathrm{C}_{\max }$ is shown to be higher in fasting than in fed conditions which reflects effect of food on the rate of drug absorption.

The results of this bioequivalence study showed the equivalence of the two studied products in terms of the rate of absorption as indicated
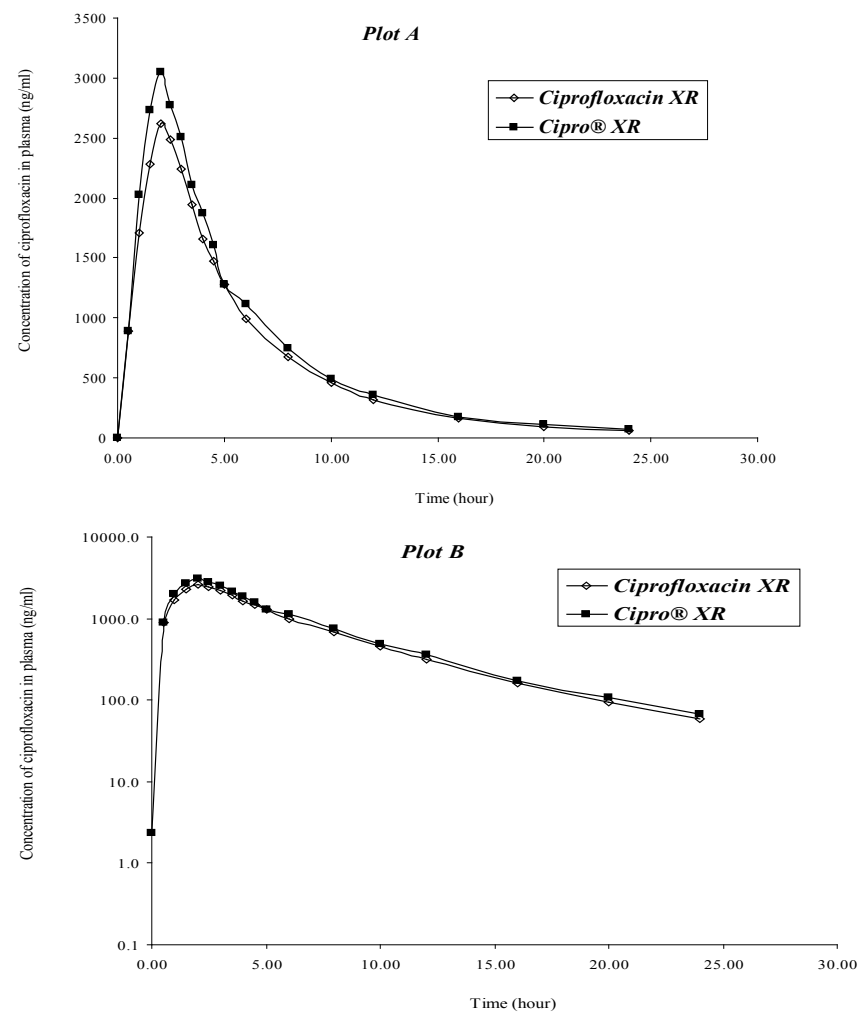

Figure 3: Ciprofloxacin mean plasma concentration after an oral dose administration of $1000 \mathrm{mg}$ Ciprofloxacin from Ciprofloxacin XR, $1000 \mathrm{mg}$ Ciprofloxacin per extended release tablet (Test Product) and Cipro ${ }^{\circledR}$ XR,1000 mg Ciprofloxacin per Tablet (Reference Product) to 24 healthy subjects under fasting conditions (Plot A: plasma conc. vs time, Plot B: log transformed plasma conc vs time).

\begin{tabular}{|c|c|c|c|}
\hline \multirow{2}{*}{$\begin{array}{c}\text { Pharmacokinetic } \\
\text { Parameter }\end{array}$} & \multicolumn{3}{|c|}{$\mathbf{9 0 \% \text { Confidence intervals of parametric means }}$} \\
\cline { 2 - 4 } & Point estimate \% & Lower Limit \% & Upper Limit \% \\
\hline $\boldsymbol{C}_{\max }$ & 102.09 & 92.77 & 112.34 \\
\hline AUC & 104.06 & 100.01 & 108.27 \\
\hline
\end{tabular}

Table 3: Bioequivalence Confidence Intervals of Ciprofloxacin for fed study (Ciprofloxacin XR Tablet the Test Product versus Cipro ${ }^{\circledR} X R$ Tablet the Reference Product).

\begin{tabular}{|c|c|c|}
\hline \multirow{2}{*}{ Pharmacokinetic Parameter } & \multicolumn{2}{|c|}{ Treatment (Mean \pm SD) } \\
\hline & Test Product & Reference Product \\
\hline$C_{\max }(n g / m l)$ & $2946 \pm 1006.38$ & $2839 \pm 684.14$ \\
\hline$A \cup C_{0 \rightarrow t}(n g \cdot h / m l)$ & $15757.3 \pm 3122.92$ & $15178.8 \pm 3238.10$ \\
\hline$A \cup C_{0 \rightarrow \infty}(n g \cdot h / m l)$ & $16421.2 \pm 3308.73$ & $15820.9 \pm 3393.12$ \\
\hline$t_{\max }(h)$ & $2.83 \pm 1.24$ & $2.70 \pm 1.33$ \\
\hline$t_{1 / 2 \mathrm{e}}(h)$ & $5.14 \pm 0.62$ & $5.26 \pm 0.69$ \\
\hline$A \cup C_{0 \rightarrow t} / A U C_{0 \rightarrow \infty} \%$ & $96.02 \pm 1.08$ & $95.96 \pm 1.14$ \\
\hline$K_{\mathrm{e}}(1 / h)$ & $0.1370 \pm 0.02$ & $0.1338 \pm 0.02$ \\
\hline
\end{tabular}

Table 4: Pharmacokinetics Parameters of Ciprofloxacin for fed study (Ciprofloxacin $X R$ Tablet the Test Product versus Cipro ${ }^{\circledR} X R$ Tablet the Reference Product).

\begin{tabular}{|c|c|c|c|}
\hline \multirow{2}{*}{$\begin{array}{c}\text { Pharmacokinetic } \\
\text { Parameter }\end{array}$} & \multicolumn{3}{|c|}{$\mathbf{9 0 \%}$ Confidence intervals of parametric means } \\
\cline { 2 - 4 } & Point estimate \% & Lower Limit \% & Upper Limit \% \\
\hline $\boldsymbol{C}_{\max }$ & 88.87 & 82.17 & 96.10 \\
\hline AUC & 87.60 & 80.38 & 95.46 \\
\hline
\end{tabular}

Table 5: Bioequivalence Confidence Intervals of Ciprofloxacin for fasting study (Ciprofloxacin XR Tablet the Test Product versus Cipro ${ }^{\circledR}$ XR Tablet the Reference Product).

\begin{tabular}{|c|c|c|}
\hline \multirow{2}{*}{ Pharmacokinetic Parameter } & \multicolumn{2}{|c|}{ Treatment (Mean \pm SD) } \\
\hline & Test Product & Reference Product \\
\hline$C_{\max }(n g / m l)$ & $2993 \pm 845.18$ & $3319 \pm 675.16$ \\
\hline$A \cup C_{0 \rightarrow t}(n g \cdot h / m l)$ & $15423.8 \pm 5431.72$ & $17163.9 \pm 4192.24$ \\
\hline$A \cup C_{0 \rightarrow \infty}(n g \cdot h / m l)$ & $16008.5 \pm 5582.25$ & $17874.2 \pm 4318.83$ \\
\hline$t_{\max }(h)$ & $2.10 \pm 0.82$ & $2.13 \pm 0.58$ \\
\hline$t_{1 / 2 \mathrm{e}}(h)$ & $5.25 \pm 1.29$ & $5.24 \pm 0.99$ \\
\hline$A \cup C_{0 \rightarrow t} / A \cup C_{0 \rightarrow \infty} \%$ & $96.23 \pm 1.24$ & $95.97 \pm 1.97$ \\
\hline$K_{e}(1 / h)$ & $0.1379 \pm 0.03$ & $0.1369 \pm 0.03$ \\
\hline
\end{tabular}

Table 6: Pharmacokinetics Parameters of Ciprofloxacin for fasting study (Ciprofloxacin XR Tablet the Test Product versus Cipro ${ }^{\circledR}$ XR Tablet the Reference Product).

by $\mathrm{C}_{\max }$ and in terms of the extent of absorption as indicated by $\mathrm{AUC}_{0-\mathrm{t}}$ and $\mathrm{AUC}_{0-\infty}$. The parametric $90 \%$ confidence intervals of the mean values for the Test/Reference ratio were in each case well within the bioequivalence acceptable boundaries of $80.00-125.00 \%$ for $\mathrm{AUC}_{0 \rightarrow t}$ and $\mathrm{C}_{\max }$ ANOVA analysis on the log-transformed data, $\mathrm{C}_{\max }, \mathrm{AUC}_{0-\mathrm{t}}$ and $\mathrm{AUC}_{0-\infty}$ and untransformed data for $\mathrm{C}_{\max }, \mathrm{AUC}_{0-\mathrm{t}}, \mathrm{AUC}_{0-\infty}, \mathrm{K}_{\mathrm{e}}, \mathrm{t}_{1 / 2 \mathrm{e}}$ and $t_{\max }$ showed that sequence effect for all these parameters did not significantly influence the outcome of the study. The mean plasma curves of both products are almost superimposable suggesting that not only $\mathrm{C}_{\max }$ and $\mathrm{AUC}_{0-\mathrm{t}}$ but also the time course of plasma levels over the whole sampling period are identical.

\section{Conclusions}

In conclusion, pharmacokinetic parameters, namely, $\mathrm{C}_{\max }, \mathrm{AUC}_{0-\mathrm{t}}$ 
Citation: Omari DM, Johary D, Salem II, Najib N, Sallam AA (2011) Bioequivalence of Two Oral Extended Release Formulations of Ciprofloxacin Tablets in HealthyMale Volunteers under Fed and Fasting Conditions. J Bioequiv Availab 3: 038-042. doi:10.4172/jbb.1000055

and $\mathrm{AUC}_{0-\infty}$, of the two ciprofloxacin $1000 \mathrm{mg}$ extended release products showed comparable values indicating that they are bioequivalent.

\section{Acknowledgement}

Great gratitude is expressed to Hikma Pharmaceuticals-Jordan for their sponsorship for this study.

\section{Referneces}

1. Aballah RM, Alam SM, Awaad FM, Dham R, El-Kersh A, et al. (2002) Bioequivalence of two brands of ciprofloxacin $750 \mathrm{mg}$ tablets (Sarf and Ciprobay) in healthy human volunteers. Drug Dev Ind Pharm 28: 423-439.

2. Azad MA, AShikullah, Latif AHM, AbulHasnat (2007) Bioequivalence and pharmacokinetic study of two formulations ciprofloxacin tablets in healthy male volunteers. J App Res 7: 150-157.

3. Bauernfeind A, Petermüller C (1983) In vitro activity of ciprofloxacin, norfloxacin and nalidixic acid. Eur J Clin Microbiol 2: 111-115.

4. Borner K, Lode H, Elvers A (1982) Determination of apalcillin and its metabolites in human body fluids by high-pressure liquid chromatography. Antimicrob Agents Chemother 22: 949-953.

5. Chin NX, Neu HC (1984) Ciprofloxacin, a quinolone carboxylic acid compound active against aerobic and anaerobic bacteria. Antimicrob Agents Chemother 25: 319-326.

6. $\mathrm{CIPRO}^{\circledR} \mathrm{XR}, \mathrm{PDR} 2007$

7. Fass R (1987) Efficacy and safety of oral ciprofloxacin for treatment of serious urinary tract infections. Antimicrob agents chemother 31: 148-150.

8. Fourcroy JL, Berner B, Chiang Y, Cramer M, Rowe L, et al. (2005) Efficacy and safety of a novel once-daily extended-release ciprofloxacin tablet formulation for treatment of uncomplicated urinary tract infection in women. Antimicrob agents chemother 49: 4137-4143.

9. Rockville MD (2002) Food and Drug Administration. Guidance for Industry: Bioavailability and Bioequivalence Studies for Orally Administered Drug Products-General Considerations.
10. http://www.fda.gov/downloads/Regulatorylnformation/Guidances/CM126833 .pdfHttp://www. fda.gov/cder/guidance/index.htm

11. Goodman LJ, Fliegelman RM, Trenholme GM, Kaplan RL (1984) Comparative in vitro activity of ciprofloxacin against Campylobacter spp. and other bacterial enteric pathogens. Antimicrob Agents Chemother 25: 504-506.

12. Hickerson AD, Carson CC (2006) The treatment of urinary tract infections and use of ciprofloxacin extended release. Expert Opin Investig Drugs 15: 519-32.

13. Malinowski H, Johnson S (2005) Bioavailability and Bioequivalence Testing in Remington's The Sciences and practice of pharmacy, $21^{\text {st }}$ edn, Lipincott Williams \&Wilkins, pp 1037-1046.

14. Meagher AK, Forrest A, Dalhoff A, Stass H, Schentag1 JJ (2004) Novel Pharmacokinetic-Pharmacodynamic model for prediction of outcomes with an extended-release formulation of ciprofloxacin. Antimicrob agents chemother. 48: 2061-2068.

15. Mirone V, Fusco F, Taglialatela D, Verze P, Di Vito C, et al. (2009) Efficacy and safety of ciprofloxacin XR $1000 \mathrm{mg}$ once daily versus ciprofloxacin $500 \mathrm{mg}$ twice daily in the treatment of complicated urinary tract infections. J Chemother 21: 651-660.

16. Steinijans V, Diletti E (1983) Statistical analysis of bioavailability studies: Parametric and nonparametric confidence intervals. Eur J Clin Pharmacol 24 127-136.

17. Talan DA, Naber KG, Palou J, Elkharrat D (2004) Extended-release ciprofloxacin (Cipro XR) for treatment of urinary tract infections. Int J Antimicrob Agents 1: S54-66.

18. Wagenlehner FM , Kinzig-Schippers M, Tischmeyer U, Wagenlehner C, Sörge F, et al. (2006) Urinary Bactericidal Activity of Extended-Release Ciprofloxacin (1,000 Milligrams) versus Levofloxacin ( 500 Milligrams) in Healthy Volunteers Receiving a Single Oral Dose. Antimicrob agents chemother 50: 3947-3949.

19. Waugh J, Keating GM (2004) Ciprofloxacin extended release: in the treatment of urinary tract infections and uncomplicated pyelonephritis. Drugs Aging 21: $55-64$ 